\title{
UTILIZAÇÃO E RECUPERAÇÃO DE SÍLICA GEL IMPREGNADA COM NITRATO DE PRATA
}

\author{
Patrícia S. S. Andreão, Rosana A. Giacomini, Alexandre M. Stumbo, Walter R. Waldman e Raimundo Braz-Filho \\ Laboratório de Ciências Químicas, Universidade Estadual do Norte Fluminense, 28013-602 Campos dos Goytacazes - RJ, Brasil \\ Carolina B. P. Ligiéro e Paulo C. M. L. Miranda* \\ Instituto de Química, Universidade Estadual de Campinas, CP 6154, 13083-970 Campinas - SP, Brasil
}

Recebido em 28/2/09; aceito em 18/6/09; publicado na web em 13/11/09

\begin{abstract}
USE AND RECYCLING OF SILICA GEL IMPREGNATED WITH SILVER NITRATE. Argentation chromatography is used to increase the selectivity of the chromatographic process, chiefly in the resolution of complex mixtures of nonpolar substances. Although efficient, this technique generates residues containing heavy metal which makes its discarding through common procedures impracticable. In the present work a simple method for recycling of silica, and also silver, from argentation chromatography is described. This procedure uses initially a treatment of $\mathrm{H}_{2} \mathrm{O}_{2} / \mathrm{HNO}_{3}$, with subsequent treatment with $\mathrm{H}_{2} \mathrm{O}_{2} / \mathrm{H}_{2} \mathrm{SO}_{4}$, allowing an efficient recycling of both components. This methodology is simple, costless, removes impurities efficiently, and does not modify retention parameters nor specific surface in a significant way.
\end{abstract}

Keywords: argentation chromatography; silica gel; recycling.

\section{INTRODUÇÃO}

A sílica-gel é uma das principais fases estacionárias empregadas na cromatografia em fase líquida para o isolamento e a purificação de substâncias orgânicas de baixa ou média polaridade. Uma eventual dificuldade na resolução de uma mistura mais complexa pode ser contornada com o aumento seletivo do poder de resolução deste adsorvente pela adição de impregnantes à sílica. Neste contexto o uso de aditivos como íons $\mathrm{Ag}(\mathrm{I})$, que tem se mostrado bastante útil na separação de compostos orgânicos insaturados, é o mais difundido. ${ }^{1}$ Entretanto, o emprego de outros sais inorgânicos é conhecido e entre estes se destacam os sais de cobre, tálio e níquel. ${ }^{2-4}$

$\mathrm{O}$ nitrato de prata associado à sílica-gel tem uma longa história de uso como suporte cromatográfico. Elberz, ${ }^{5}$ em 1937, e Lucas e Winstein, ${ }^{6}$ em 1938, foram os primeiros a reportar que íons prata poderiam se complexar com alquenos. No entanto, seu emprego em cromatografia teve início apenas alguns anos mais tarde, tendo sido intensamente usado na década de 1960. Nas décadas seguintes, entretanto, sua utilização apresentou um declínio. ${ }^{1}$ Apesar disso até hoje a técnica ainda é empregada e tem sido importante para a separação de triterpenos, ${ }^{7}$ esteroides,${ }^{78}$ triglicerídeos ${ }^{9}$ lipídeos, ${ }^{10}$ feromônios, ${ }^{11}$ e na resolução de misturas de terpenos com estruturas muito semelhantes. ${ }^{12}$ Os fenômenos envolvidos nas interações que regem a diferença entre as afinidades dos analitos com os íons $\mathrm{Ag}(\mathrm{I})$ impregnados na fase estácionária são, em ordem crescente de prioridade, os seguintes: a formação de complexos com ligações insaturadas, interações com grupos funcionais polares que contêm heteroátomos hidrogenados $\left(\mathrm{OH}, \mathrm{NH}_{2}\right.$ e $\left.\mathrm{CO}_{2} \mathrm{H}\right)$, e interações com outros grupos polares. No caso das ligações múltiplas entre átomos de carbono fatores como a conjugação, densidade eletrônica e impedimento estéreo são importantes na interação do analito com a fase estacionária. Compostos com ligações múltiplas conjugadas e com maior densidade eletrônica nestas ligações tendem a formar os complexos mais estáveis e, portanto, a possuir maior afinidade pela fase estacionária. Complementarmente, os compostos com ligações múltiplas isoladas, e que possuem maior restrição estérea e menor densidade eletrônica, tendem a ser menos retidos que os primeiros. Os resultados experimentais que descre-

\footnotetext{
*e-mail:miranda@iqm.unicamp.br
}

vem este padrão de comportamento são plenamente explicados pela química teórica. ${ }^{11,13-15}$

Em nosso laboratório, a cromatografia que usa íons prata impregnados em sílica gel mostrou-se bastante efetiva na separação de quatro isômeros diterpênicos insaturados presentes na fração ácida esterificada do extrato hexânico do epicarpo de Hymenaea stigonocarpa. Entre várias substâncias, foram isolados e identificados os diterpenos: caur-16-en-19-ato de metila (1), caur-15-en-19-ato de metila (2), ozato de metila (3) e isoozato de metila (4) (Figura 1) cuja separação por cromatografia em coluna empregando sílica convencional é dificílima.
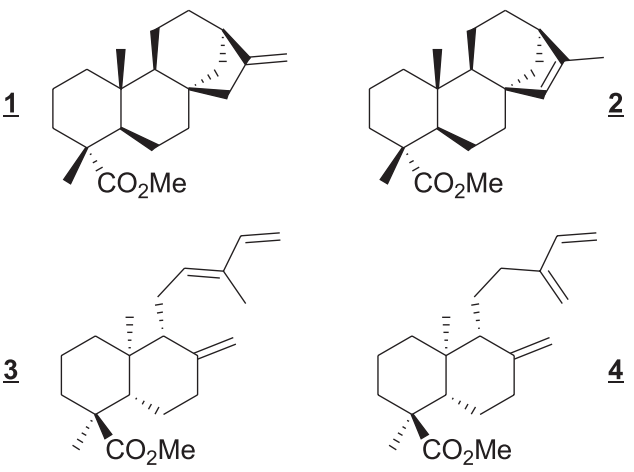

Figura 1. Substâncias isoladas da fração ácida do extrato hexânico do epicarpo de Hymenaea stigonocarpa após esterificação. Empregou-se neste processo a cromatografia em fase líquida em leito de sílica impregnado com nitrato de prata

A utilização dessa técnica em grande escala nos laboratórios gera, entretanto, alguns problemas. A quantidade de resíduo de sílica contaminada com compostos orgânicos, e ainda no caso da sílica impregnada com prata, o resíduo de prata, pode atingir grandes proporções. Tal fato dificulta o descarte e torna o processo bastante dispendioso, já que esta apresenta um alto custo. As técnicas para recuperação de sílica difundidas na literatura baseadas em processos oxidativos avançados com $\mathrm{H}_{2} \mathrm{O}_{2} /$ luz solar ${ }^{16}$ ou em oxidação com $\mathrm{H}_{2} \mathrm{O}_{2}$ / $\mathrm{H}_{2} \mathrm{SO}_{4},{ }^{17}$ assim como a lavagem com metanol e água ${ }^{18}$ não forneceram 
resultados satisfatórios, sendo incapazes de remover completamente os íons Ag(I). Procurando minimizar estes problemas, o objetivo deste trabalho foi divulgar uma metodologia simples, mas eficiente e de baixo custo, para recuperar tanto a sílica gel quanto o metal $(\mathrm{Ag})$ gerados no laboratório pelo emprego da técnica de impregnação da fase estacionária por este metal.

\section{PARTE EXPERIMENTAL}

\section{Materiais}

Empregou-se a sílica gel $60\left(\mathrm{Merck}^{\circledR}\right)$ com granulometria entre 70 e 230 mesh $(63$ e $200 \mu \mathrm{m})$. Os reagentes e os solventes utilizados (grau HPLC), todos da marca $\operatorname{Vetec}^{\circledR}$, foram utilizados como comercializados.

\section{Equipamentos}

A área específica, o volume de poros e a distribuição de diâmetros dos poros foram determinados por fisissorção de nitrogênio, empregando-se um equipamento Autosorb 1C da Quantachrome ${ }^{\circledR}$. As amostras foram previamente aquecidas sob vácuo, a $373 \mathrm{~K}$, durante $3 \mathrm{~h}$. As isotermas de adsorção/dessorção foram obtidas a $77 \mathrm{~K}$. As áreas específicas foram determinadas pelo modelo BET (pressões relativas entre 0,05 e 0,30 ) e a distribuição de diâmetro dos poros foi calculada pela Equação de Barrett-Joyner-Halenda (BJH) no ramo da dessorção, ambas através do programa Autosorb for Windows ${ }^{\circledR}$, versão 1.24.

As análises termogravimétricas foram realizadas em uma balança termogravimétrica SDT 2960 DSC/TGA simultâneos da TA Instruments ${ }^{\circledR}$ sob atmosfera oxidante. Os dados foram tratados e as curvas foram construídas com o programa Origin 6.0 da Microcal $^{\circledR}$.

As análises de HPLC foram realizadas em um cromatógrafo Shimadzu SPD-M10AVP com detector espectrofotométrico de arranjo de diodos e equipado com uma coluna ODS-Lichrospher com $150 \mathrm{~mm}$ x 4,6 mm da Regis Technologies ${ }^{\circledR}$. De forma geral, uma alíquota de $20 \mu \mathrm{L}$ dos resíduos de tratamento foi injetada em modo isocrático com $100 \%$ de metanol. Já as análises cromatográficas em fase gasosa foram realizadas em um cromatógrafo Shimadzu QP-17 acoplado a um espectrômetro de massas QP-5050, empregando uma coluna capilar HP-5 com $30 \mathrm{~m}$ de comprimento e hélio como gás de arraste.

As análises de fluorescência de raios-X foram realizadas em um espectrômetro de raios- $X$ de energia dispersiva da Shimadzu modelo EDX 700 equipado com um tubo de ródio e um detector de silício(lítio) semicondutor.

\section{Impregnação da sílica gel com nitrato de prata e sua utilização}

Pesaram-se $12 \mathrm{~g}$ de gel de sílica gel em um béquer de forma baixa. Em outro recipiente, protegido da luz, pesou-se $1,3 \mathrm{~g}$ de $\mathrm{AgNO}_{3}$. Diluiu-se este sal em aproximadamente 5,0 $\mathrm{mL}$ de água e verteu-se a solução no recipiente que continha a sílica. Protegeu-se este recipiente da luz com folhas de papel alumínio, deixando na parte superior pequenos orifícios para a saída do vapor de água. Em seguida, este material foi deixado em uma estufa por 3 dias a $75{ }^{\circ} \mathrm{C}$ para ativação.

Em ambiente iluminado apenas com luz vermelha, uma coluna foi empacotada com a sílica impregnada com prata através da suspensão da fase estacionária em hexano. Após a compactação do leito cromatográfico a mistura dos ésteres 1, 2, 3 e $\mathbf{4}$ foi adicionada na forma de uma pastilha preparada em sílica sem nitrato de prata. ${ }^{19} \mathrm{~A}$ coluna foi eluída inicialmente com hexano. Aumentou-se lentamente a polaridade do eluente, indo de hexano puro até uma solução de $50 \%$ de acetato de etila em hexano. A resolução da mistura foi acompanhada por um aparelho de cromatografia gasosa, fornecendo as frações que foram reunidas de acordo com sua composição. Ao final do processo foi possível obter os quatro diterpenos puros.

\section{Recuperação da sílica gel impregnada com nitrato de prata}

Trataram-se $100 \mathrm{~g}$ de sílica gel 60 impregnada com nitrato de prata com $200 \mathrm{~mL}$ de $\mathrm{H}_{2} \mathrm{O}_{2} 30 \%$ e $11,5 \mathrm{~mL}$ de $\mathrm{HNO}_{3} 65 \%$ por 10 dias. A adição do peróxido de hidrogênio deve ser feita lentamente e em banho de gelo, devido ao grande aquecimento do meio, e em uma capela com boa exaustão. Durante o tratamento a amostra foi periodicamente homogeneizada com um bastão de vidro. Ao final deste período, a sílica foi decantada, lavada com $100 \mathrm{~mL}$ de água destilada e filtrada em Büchner. Lavou-se a sílica por mais cinco vezes com porções de $100 \mathrm{~mL}$ de água destilada, sendo que na última filtração o pH do filtrado já se encontrava próximo a 6. Reuniram-se todos os filtrados e adicionou-se solução saturada de $\mathrm{NaCl}$ neste para precipitar a prata na forma de $\mathrm{AgCl}$. Ainda no Büchner, lavou-se a sílica com $200 \mathrm{~mL}$ de metanol para a remoção de alguns resíduos orgânicos polares menos solúveis em água.

Adicionaram-se à sílica gel seca obtida no tratamento anterior $200 \mathrm{~mL}$ de $\mathrm{H}_{2} \mathrm{O}_{2}$ e $1 \mathrm{~mL}$ de $\mathrm{H}_{2} \mathrm{SO}_{4}$ concentrado. Deixou-se a mistura descansar por mais 10 dias, entretanto, com homogeneizações periódicas. O material foi filtrado e lavado sucessivas vezes com porções de $100 \mathrm{~mL}$ de água destilada, de forma semelhante à anterior, até o clareamento da sílica gel. Ativou-se a sílica gel obtida por este processo em estufa por $12 \mathrm{~h}$ a $120^{\circ} \mathrm{C}$.

\section{RESULTADOS E DISCUSSÃO}

Aplicando-se a técnica da cromatografia em coluna com sílica gel impregnada com íons $\mathrm{Ag}(\mathrm{I})$ foram isolados e identificados, entre várias substâncias, os diterpenos caur-16-en-19-ato de metila (1), caur-15-en-19-ato de metila (2), ozato de metila (3) e isoozato de metila (4), mostrados na Figura 1. A separação por cromatografia em coluna destas substâncias empregando sílica convencional é dificílima e, mesmo quando possível, requer quantidades muito grandes de fase estacionária, elevando o gasto e o tempo necessário para a separação cromatográfica. O processo de resolução cromatográfica desta mistura empregando a sílica modificada precisou ser acompanhado por um aparelho de cromatografia gasosa, uma vez que não foi possível separar as diferentes substâncias em CCD de sílica convencional. Este acompanhamento também foi útil para certificar que não houve a produção de artefatos durante a cromatografia em coluna de sílica modificada pelos íons prata, nem a modificação da composição original da mistura.

Com relação à recuperação da fase estacionária, embora o peróxido de hidrogênio seja um bom oxidante $\left(E_{\text {reducão }}^{0}=1,77 \mathrm{eV}\right)$, possuindo potencial de oxidação suficiente para oxidar a prata $\left(E_{\text {redução }}^{0}=0,80 \mathrm{eV}\right)$, e tenha sido empregado anteriormente na recuperação de sílica gel, seu uso isolado ou com ácido sulfúrico mostrou-se insuficiente para a remoção da prata. ${ }^{16,17}$ Tanto o óxido de prata quanto o sulfato de prata são insolúveis e o emprego destas técnicas não é adequado para a completa remoção do metal pesado. Entretanto, se o ácido empregado for o $\mathrm{HNO}_{3}$ este problema é contornado, embora se esteja incluindo outra espécie oxidante no meio: o nitrato $\left(E_{\text {reduc̃ao }}^{0}=0,94 \mathrm{eV}\right.$, para a equação de redução $\left.\mathrm{NO}_{3(a q)}^{-}+3 \mathrm{H}^{+}+2 e^{-} \rightarrow \mathrm{HNO}_{2(a q)}+\mathrm{H}_{2} \mathrm{O}\right)$. Tanto que durante este tratamento a liberação de gases de coloração castanha é observada, e este procedimento necessitou ser realizado em uma capela com ventilação eficiente.

$\mathrm{O}$ íon $\mathrm{Ag}(\mathrm{I})$ liberado nas reações de óxido-redução foi recuperado pela precipitação com cloreto $\left(K_{P S(A g C l)}=1,8 \times 10^{-10}\right)$. A taxa de recuperação foi $93,8 \%$ em média, entretanto, não se observou a presença do metal pesado na sílica gel recuperada pela técnica de fluorescência de raios-X, como pode ser observado na Tabela 1 . O procedimento 
empregado para a recuperação das amostras $\mathbf{R}$ (a impregnada com íons $\mathrm{Ag}(\mathrm{I})$ e posteriormente recuperada com $\mathrm{HNO}_{3} / \mathrm{H}_{2} \mathrm{O}_{2}$ e depois $\mathrm{H}_{2} \mathrm{SO}_{4} / \mathrm{H}_{2} \mathrm{O}_{2}$ ) e $\mathbf{L}$ (a tratada com $\left.\mathrm{H}_{2} \mathrm{SO}_{4} / \mathrm{H}_{2} \mathrm{O}_{2}\right)^{17}$ promoveu a redução da quantidade de impurezas solúveis da sílica-gel nova $(\mathbf{N})$, embora tenha aumentado em $10 \%$ o teor de enxofre original.

Tabela 1. Composição das amostras de sílica empregando a fluorescência de raios-X

\begin{tabular}{ccccccc}
\hline Amostra & $\% \mathrm{Ag}$ & $\% \mathrm{Si}$ & $\% \mathrm{~S}$ & $\% \mathrm{Ca}$ & $\% \mathrm{Fe}$ & $\% \mathrm{~K}$ \\
\hline Sílica N & 0,000 & 92,407 & 5,496 & 0,550 & 0,615 & 0,932 \\
Sílica R & 0,000 & 93,962 & 6,038 & 0,000 & 0,000 & 0,000 \\
Sílica L & 0,000 & 93,983 & 6,017 & 0,000 & 0,000 & 0,000 \\
\hline
\end{tabular}

Para aferir a qualidade da fase estacionária recuperada avaliaramse as isotermas de adsorção/dessorção de nitrogênio para uma amostra de sílica gel $60\left(\right.$ Merck $\left.^{\circledR}\right)$ com granulometria entre 70 e 230 mesh nova $(\mathbf{N})$, uma amostra desta mesma sílica impregnada com prata e posteriormente recuperada $(\mathbf{R})$ e uma amostra da sílica gel usada e recuperada segundo a literatura $(\mathbf{L})$. O método de recuperação da literatura escolhido foi o que utiliza $\mathrm{H}_{2} \mathrm{O}_{2}$ e ácido sulfúrico, e os dados estão descritos na Tabela 2.

Tabela 2. Caracterização textural das amostras de sílica antes e após tratamentos

\begin{tabular}{lccc}
\hline Amostra & $\begin{array}{c}\text { Área BET } \\
\left(\mathrm{m}^{2} \cdot \mathrm{g}^{-1}\right)\end{array}$ & $\begin{array}{c}\text { Volume de poros } \\
\left(\mathrm{cm}^{3} \cdot \mathrm{g}^{-1}\right)\end{array}$ & $\begin{array}{c}\text { Diâmetro médio } \\
\text { de poros }(\AA)\end{array}$ \\
\hline Sílica $\mathbf{N}$ & 372 & 0,67 & 62 \\
Sílica $\mathbf{R}$ & 346 & 0,61 & 62 \\
Sílica $\mathbf{L}$ & 337 & 0,60 & 62 \\
\hline
\end{tabular}

As isotermas de adsorção/dessorção de nitrogênio obtidas para todas as amostras foram praticamente idênticas, do tipo IV, segundo a nomenclatura da IUPAC, ${ }^{20}$ típicas de materiais mesoporosos. A histerese observada é do tipo $\mathrm{H} 1$, na qual os ramos de adsorção e dessorção são quase paralelos, geralmente associada a materiais porosos constituídos por aglomerados de partículas esféricas de tamanho uniforme. ${ }^{20} \mathrm{~A}$ distribuição de poros é monomodal, em torno de um valor médio de $62 \AA$. A quase totalidade dos poros apresenta diâmetros entre 25 e $150 \AA$.

As sílicas tratadas apresentaram um decréscimo de área específica e de volume de poros de aproximadamente $10 \%$ em relação ao material de origem, como mostram os dados da Tabela 2. O resultado foi praticamente o mesmo para todos os tratamentos testados, dentro da margem de erro da técnica $( \pm 2 \%)$. O valor do diâmetro médio de poros não se alterou com o tratamento em nenhum dos casos.

A redução da área específica e do volume de poros poderia ser explicada por uma obstrução parcial da estrutura porosa, causada pelo tratamento térmico a que as amostras foram submetidas. Esta obstrução foi aleatória não tendo alargado a distribuição do tamanho dos poros, nem produzido mais de um valor máximo. Esta obstrução ocorreu em aproximadamente $10 \%$ do sistema de poros causando a diminuição proporcional da área específica e do volume total, sem afetar a distribuição dos mesmos.

Analisando o gráfico da derivada da perda de massa em função da temperatura, Figura 2, observa-se que todos os processos de perda massa acontecem nas mesmas temperaturas. Todas as amostras têm exatamente os mesmos processos de perda de massa, variando apenas a sua intensidade. Portanto, é possível excluir a presença de carbono nas amostras, uma vez que elas foram aquecidas até $800^{\circ} \mathrm{C}$ em atmosfera oxidante. A maior diferença de perda de massa apresentada entre os termogramas foi na faixa de 50 a $170{ }^{\circ} \mathrm{C}$, onde a sílica $\mathbf{N}$ proporcionou as maiores taxas de perda em função de seu maior grau de hidratação. As curvas dos termogramas das amostras de sílica $\mathbf{R}$ e $\mathbf{L}$ mostraram-se idênticas entre 170 e $800{ }^{\circ} \mathrm{C}$. Dentro desta faixa as maiores diferenças, quando estas duas são comparadas com a sílica $\mathbf{N}$, ficaram em torno de $0,01 \%$, o que comprova a eficiência dos processos de recuperação empregados.

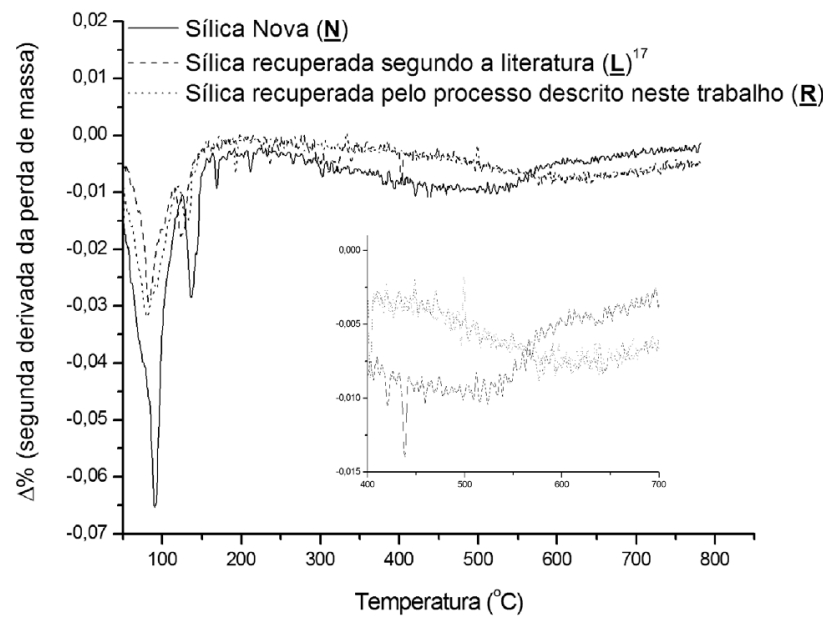

Figura 2. Gráfico da derivada da perda de massa em função da temperatura obtido na análise termogravimétrica em atmosfera oxidante das amostras de sílica antes e após tratamentos

A análise de HPLC em fase reversa (octadecilsilano) com detector de arranjo de diodos de um extrato metanólico de todas as três amostras (sílicas $\mathbf{N}, \mathbf{R}$ e $\mathbf{L}$ ) forneceu cromatogramas idênticos e absolutamente livres de contaminação. A resolução na separação cromatográfica em coluna com as sílicas $\mathbf{N}, \mathbf{R}$ e $\mathbf{L}$ de uma amostra de $\alpha$-naftol e $\beta$-naftol, descrito na literatura como parâmetro de comparação de eficiências de fases estacionárias, ${ }^{18}$ foi idêntica.

\section{CONCLUSÃO}

Em resumo, o uso da sílica-gel impregnada com íons $\mathrm{Ag}(\mathrm{I})$ mostrou-se muito útil na separação dos compostos $\mathbf{1}, \mathbf{2}, \mathbf{3}$ e 4, que possuem estruturas muito próximas e são de separação muito difícil pela técnica convencional. Com esta técnica houve uma redução significativa da quantidade de fase estacionária empregada e do tempo requerido para a resolução da mistura. A geração de um resíduo de sílica contaminado com metal pesado, que seria um problema ambiental severo, foi contornada pelo tratamento da fase estacionária primeiramente com $\mathrm{H}_{2} \mathrm{O}_{2} / \mathrm{HNO}_{3}$ e, posteriormente, com $\mathrm{H}_{2} \mathrm{O}_{2} / \mathrm{H}_{2} \mathrm{SO}_{4}$, permitindo a recuperação eficiente tanto da sílica quanto da prata. Análises quantitativas e qualitativas de composição e eficiência não mostraram diferenças significativas entre a sílica gel nova, a sílica gel impregnada com prata e posteriormente recuperada pela técnica aqui descrita e a sílica gel tratada segundo a literatura. A metodologia aqui descrita e empregada na recuperação da sílica impregnada com $\operatorname{Ag}(\mathrm{I})$ é um tratamento simples, remove com eficiência as impurezas presentes na mesma, não modifica significativamente a superfície da sílica, não altera parâmetros de retenção e é de baixo custo.

\section{AGRADECIMENTOS}

Ao IQ-UNICAMP pelo suporte e facilidades concedidas e à FAPESP pelo apoio financeiro. C. B. P. Ligiéro agradece ao CNPq e P. S. S. Andreão à UENF pelas bolsas concedidas. 


\section{REFERÊNCIAS E NOTAS}

1. Williams, C. M.; Mander, L. M.; Tetrahedron 2001, 57, 425.

2. Cechi, L.; Malaspina, P.; Anal. Biochem. 1991, 192, 219.

3. Siouffi, A. M.; Traynard, J. C.; J. Chromatogr. Sci. 1977, 15, 469.

4. Bhushan, R.; Thiong'o, G. T.; Biomed. Chromatogr. 2002, 16, 165.

5. Eberz, W. F.; Welge, H. J.; Yost, D. M.; Lucas, H. J.; J. Am. Chem. Soc. 1937, 59, 45.

6. Winstein, S.; Lucas, J. H.; J. Am. Chem. Soc. 1938, 60, 836.

7. Li, T. S.; Li, J. T.; Li, H. Z.; J. Chromatogr., A 1995, 715, 372.

8. Jarusiewicz, J.; Sherma, J.; Fried, B.; J. Liq. Chromatogr. Relat. Technol. 2005, 28, 2607.

9. Damyanova, B. N.; J. Liq. Chromatogr. Relat. Technol. 1999, 22, 1513.

10. Momchilova, S.; Damyanova, B. N.; J. Sep. Sci. 2003, 26, 261.

11. van Beek, T. A.; Subrtova, D.; Phytochem. Anal. 1995, 6, 1.

12. Nogueira, R. T.; Giacomini, R. A.; Shepherd, G. J.; Imamura, P. M.; J. Braz. Chem. Soc. 2002, 13, 389.
13. Damyanova, B. N.; Christie, W. W.; Herslöf, B.; J. Chromatogr., A 1996, $749,47$.

14. Ho, Y. P.; Yang, Y. C.; Klippenstein, S. J.; Dunbar, R. C.; J. Phys. Chem. A 1997, 101, 3338.

15. Kaneti, J.; de Smet, L. C. P. M.; Boom, R.; Zuilhof, H.; Sudhölter, E. J. R.; J. Phys. Chem. A 2002, 106, 11197.

16. Teixeira, S. C. G.; Mathias, L.; Canela, M. C.; Quim. Nova 2003, 26, 931.

17. Riehl, C. A. S.; Pinto, A. C.; Quim. Nova 1988, 11, 329.

18. Loureiro, A. P.; Souza, J. A.; Aparecido, D.; Fernandes, J. B.; Quim. Nova 1991, 14, 112.

19. A mistura dos ésteres $\mathbf{1}, \mathbf{2}, \mathbf{3}$ e $\mathbf{4}$ foi obtida do extrato hexânico do epicarpo de Hymenaea stigonocarpa por eluição em coluna cromatográfica com sílica gel $60\left(\right.$ Merck $\left.^{\circledR}\right)$ de granulometria entre 70 e 230 mesh. Este sistema foi incapaz de resolver a mistura mesmo realizando-se eluições sucessivas nas mesmas condições.

20. Sing, K. S. W.; Everett, D. H.; Haul, R. A. W.; Moscou, L.; Pierotti, R. A.; Rouquerol, J.; Siemieniewska, T.; Pure Appl. Chem. 1985, 57, 603. 